\title{
REGULARITIES OF YOUNGSTER FREE TIME PHYSICAL ACTIVITY IN A LATVIAN SECONDARY SCHOOL
}

\author{
Monta Jakovleva, Ieva Rudzinska \\ Latvian Academy of Sport Education, Riga, Latvia
}

\begin{abstract}
Background. Article investigates youngster physical activity (PA) habits, finding tendencies of PA participation, factors promoting and impeding it.

Methods. The methods include literature analysis, cross-sectional study with self-reported questionnaire consisting of 11 questions and statements about most popular leisure sports, frequency, venues, significant others, and neighbourhood influence. The questionnaire, based on EU Special Eurobarometer 412 "Sport and Physical Activity", research in Northern and Eastern countries, as well as in the Netherlands, was sent by e-mail to 91 Grade 10 subjects in a Latvian mainstream secondary school in the academic year of 2015/2016; the response rate was $60 \%$. The statistical analysis was carried out with Index method and SPSS software.

Results. The Cronbach's alpha for neighbourhood section (5 items) of the questionnaire was . 74 . The validity of the questionnaire was based on the consideration that the questions were drawn from surveys, described in reliable sources. Most of the students with friends or alone did three sports at sport schools $(69.50 \%)$, as well as in parks, woods, seaside, at home, most popular sports were team games (basketball, volleyball), winter sports (skiing and snowboarding), fitness sports (running), strength sports (gym workout) and gymnastics. Statistically significant, medium strong correlations were found between good relations with neighbours and high level of well-being $(r=.38, p=.05)$.

Conclusion. The student choice to practice team games and gymnastics might be influenced by traditional youngster values and their status as trendy sports, but winter sports in Latvia traditionally are among the most popular ones. Good neighbourhood relations could help youngsters be more physically active.
\end{abstract}

Keywords: mainstream school students, leisure sports, neighbourhood social capital.

\section{INTRODUCTION}

$\mathrm{T}$ The aim of the article was to summarize the methods of researching youngster physical activity (PA) habits, find tendencies characterizing youngster PA participation and factors promoting and impeding it in a Latvian mainstream secondary school.

Note: In this article PA is used a s a synonym to the term "sports", since in EU legislation "sport" is defined as all forms of physical activity, which, through casual or organized participation, aim at expressing or improving physical fitness and mental well-being, forming social relationships or obtaining results in competition at all levels (European Sports Charter Article 2, 1992).

Adolescent and youngster free time physical activity habits are widely researched on European Union (EU) level (General Practice Physical Activity Questionnaire, EU Special Eurobarometer 412 "Sport and Physical Activity" (2014)), as well as in separate European and Eastern countries, e.g. Dutch adolescent free time sports participation in relation to neighbourhood social capital and availability of sports facilities (Prins, Mohnen, van Lenthe, Brug, J., \& Oenema 2012), and Arab Teens 
Lifestyle Questionnaire (ATLS, revised 2013). Compared with EU Special Eurobarometer Arab Teens Lifestyle Questionnaire is more lifestyle oriented, it assesses lifestyle habits, including PA, sedentary behaviours and dietary habits.

In EU Special Eurobarometer has drawn the conclusion that the proportion of citizens who never exercise or play sport from year 2009 to year 2013 has even slightly increased (from 39 to $42 \%$ ). Most of PA the activity takes place in informal settings: parks and outdoors $(40 \%)$ at home $(36 \%)$, on the journey between home and school, work, or shops (25\%). Considerably less people exercise at health or fitness centres (15\%), sport clubs (13\%) and sport centres (8\%), at work (13\%), and at school or university $(5 \%)$. However, engaging in a park or outdoors is less common among young people (33\%), more popular being school or university $(23 \%)$. In EU younger people are more likely to use formal settings (22\% among 15-24 year olds), the use of sport clubs is particularly high among men aged 15-24. In Eastern European countries PA at home and engaging in PA at work are popular activities.

Considering support for sport participation in citizen local area, it has been found that most EU citizens feel that they have opportunities to be physically active, but there are mixed views on the level of support provided by local authorities. Even $76 \%$ of EU citizens either totally agree or tend to agree that their local area provides them with opportunities to be physically active. In Latvia more people than in 2009 agree that local authorities are not doing enough in this respect. People paying bills with difficulties and younger people are more likely to think that local authorities are not doing enough, especially negative in this respect are young women $-46 \%$ of 15-24-year-old women agree with the statement.

Yang, Telama, Leino, and Viikari, (1999) emphasized the importance of PA in the aspect of socialization, working life, economy and education, finding that social and behavioural factors in early life may be more important than early biological characteristics in determining activity levels in young adolescents. Adolescent participation in the intensive endurance sports was found to be most beneficial with respect to the enhancement of adult physical activity.

Vilhjalmsson and Thorlindsson's (1998) investigation showed that adolescent PA was found to be closely related to significant others' physical activity. The results suggest that socialization into PA depends on the agent and emotional vs nonemotional context. Male sex and higher social class were correlated with more PA.

Tammelin, Näyhä, Hills, and Järvelin (2003) and Telama et al. (2005) focused on tracking PA from childhood to adulthood. Participation in sports at least once a week among females and twice a week among males was associated with high level of physical activity in later life.

World Health Organization (2013), Pinto Pereira, Li, and Power (2014) and Bosdriesz, Witvliet, and Visscher (2012) raised the question of interventions to broaden PA activity participation.

\section{METHODS}

The methods include literature analysis, crosssectional study with self-reported questionnaire about youngster free time PA in a Latvian mainstream secondary school, and the response statistical analysis with index method and SPSS software. The survey was carried out by means of an on-line questionnaire, consisting of 11 questions and sent to respondents by e-mail. According to Sheehan (2001), the acceptable response rate for on-line questionnaires was set at $40 \%$, rate of $50 \%$ was considered to be good, and rate of $60 \%$ was considered to be very good.

The validity of the questionnaire was based on the consideration that the questions were drawn from surveys described in reliable sources summarized above. In the survey, there were questions included about the most popular sports or PA about adolescents, as well as frequency of practicing them, places of engaging in them, and important others who adolescents and youngsters do sports with, as well as about their social neighbourhood.

The respondents were asked to list three sports they did in the week before performing survey. The survey was carried on in January 2016; in Latvia at that time it was possible to do alongside with others also winter sports. Taking as the foundation similar investigations on the European Union level, as well as in some European and Eastern countries, the frequency of practicing PA was investigated on a weekly basis. The places where adolescents could do PA outside school included sport school, wood, park, sport club, other places; ways of doing sports included - being alone, with a friend, or with a group of friends. 
In the second part of the questionnaire, adolescents (from totally disagree to fully agree) had to respond to the statements on a 5 point Likert scale as follows: In my neighbourhood everyone can do sport he/she likes; People's relations in my neighbourhood are good; In my neighbourhood people help each other and support each other; The household level of well-being in my neighbourhood is high; In my neighbourhood criminality level is low; In my neighbourhood the traffic is safe.

The first four questions were chosen to tap possible factors promoting PA participation; the last two - possible factors impeding it. If in the neighbourhood people help and support each other, there is high level of well-being, then youngsters could be more likely to engage in leisure time PA. If the community provides the opportunities to do free time PA, youngsters are more likely to use them. If the traffic is not safe and around are a lot of criminals, adolescents could be less likely to engage in free time PA (Prins et al., 2012).

Adolescent background was investigated as to their age, gender, living conditions (house/flat, years of living in Latvia), country of birth (Latvia or other country) and parent country of birth (Latvia or other country). The last two items were chosen to find any possible influence of adolescent and their family migration on PA habits.

Research sample. For the survey we chose a mainstream secondary school situated in the outskirts of the capital, well-known in the country for being physical activity and health oriented. The questionnaire was sent by e-mail to 91 Grade 10 students in January, 2016. The questionnaire was filled in by 55 subjects, the response rate was $60 \%$, or very good according to Sheehan scale. From 55 students $30(54.55 \%)$ were men, 25 - women (45.45\%), their age being from 15 to 17 and above. 40 students $(72.73 \%)$ were 16 years old, 14 were 17 years old (25.45\%), and 1 was older than 17 (1.82\%). that:

Adolescent background investigation revealed

1. All the students (55) were born in Latvia.

2. About a half of the students (27) lived in a house, and 28 - in a flat.

3. In their present place, 20 students $(36.36 \%)$ have lived from 16-20 years, 17 students (30.91\%) from 1 to 5 years, 11 students $(20.00 \%)$ - from 6 to 10 years, and $7(12.73 \%)$ - from 11 to 15 years.

4. All the students' parents were born in Latvia. Only three parents of the students were born outside Latvia.
Statistical methods. Most popular sports adolescents did were characterized with the help of Index of Sport Participation. The latter was determined using index method, described in Geske \& Grīnfelds monograph (Geske \& Grīnfelds, 2006) as a tool highlighting considerable relationships, being both relatively simple and effective.

Index of Sport Participation (SP) was calculated summing up student participation in ten sports or groups of sports. High $(\mathrm{SPh})$ index meant that sports or groups of sports were practiced by more than 10 students $(n>10)$; medium (SPm) - by 7 to 10 students $(n=7-10)$, and low (SPl) - by less than 7 students $(n<7)$.

The frequency of doing the first, second and third mentioned sport on weekly basis, place of doing sport, as well as people who adolescents did sports with, and their neighbourhood analysis was performed with IBM SPSS V.20 program. In data processing, we applied descriptive and non-parametric methods: Chi-square, Pearson correlation. For the research we chose the $95 \%$ $(p<.05)$ confidence interval. Cronbach's alpha or the reliability coefficient in the part of the questionnaire, aiming at collecting information about youngster neighbourhood (5 items), was .74.

\section{RESULTS}

Most popular sports. Most popular sports students did on a weekly basis were summarized in 20 different sports or groups of sports as follows: 1) basketball, 2) football, 3) volleyball and beach volleyball, 4) hockey, 5) floorball and rugby, 6) cross-country, downhill skiing and snowboarding 7) skating, 8) swimming, 9) walking, 10) race walking, 11) running, 12) dancing, folk dances 13) gym, fitness, physical exercises 14) tennis and badminton, 15) cycling, 16) athletics, 17) gymnastics, acrobatics, aerobics, 18) orienteering, 19) kickboxing and 20) chess.

High sport participation index (SPh) was found to refer to basketball ( $n=18,32.73 \%)$, volleyball, skiing and snowboarding, running, working out in the gym $(n=13,23.64 \%)$, gymnastics $(n=11,20.00 \%)$. Medium sport participation index (SPm) characterized football, dancing, walking. Low sport participation index (SPl) was found to refer to all other sports, among them hockey and swimming.

Frequency of doing first, second and third mentioned sport on a weekly basis. Figure 1 shows 


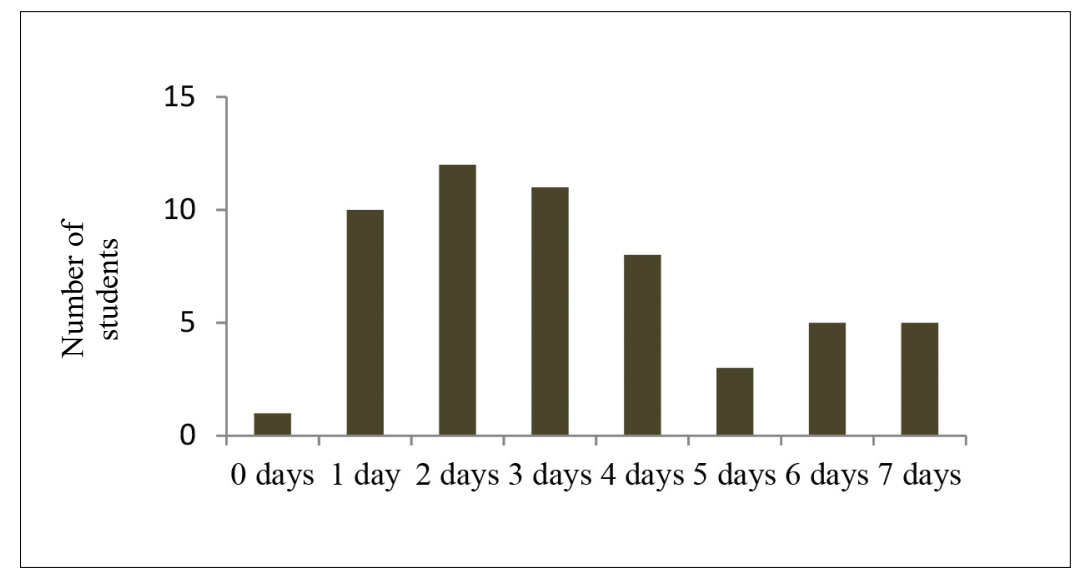

Figure 1. Frequency of practicing the first mentioned sport on a weekly basis

that most students practiced the first mentioned sport 2-3 days a week, the second maximum is at 6-7 days a week.

Figure 2 shows that second mentioned sport most of adolescents was practiced from one to two, and even 0 days a week. Besides, the tendency curve explicitly shows that the frequency of doing the second sport is falling.

Figure 3 shows that the maximum number of students did the third mentioned sport just once and 0 days a week, and the drop of the tendency curve is even more pronounced than in the previous graph.
Places of doing sports. Students do leisure time sports in sport schools, parks, woods, sport clubs and other places - in the stadium, in the gym, on the skating rink, at home, on the sand, at the sea, on the mountain/hill. Even 38 students (69.09\%) have chosen sport schools as the place of doing their first sport, 19 students $(34.54 \%)$ have chosen wood and park, 27 students $(49.09 \%)$ - sport club, $26(47.27 \%)$ prefer to do their first sport in different from abovementioned places. Total number of students exceeds $100 \%$, because many of them practice their first sport in several or even all of the mentioned places.
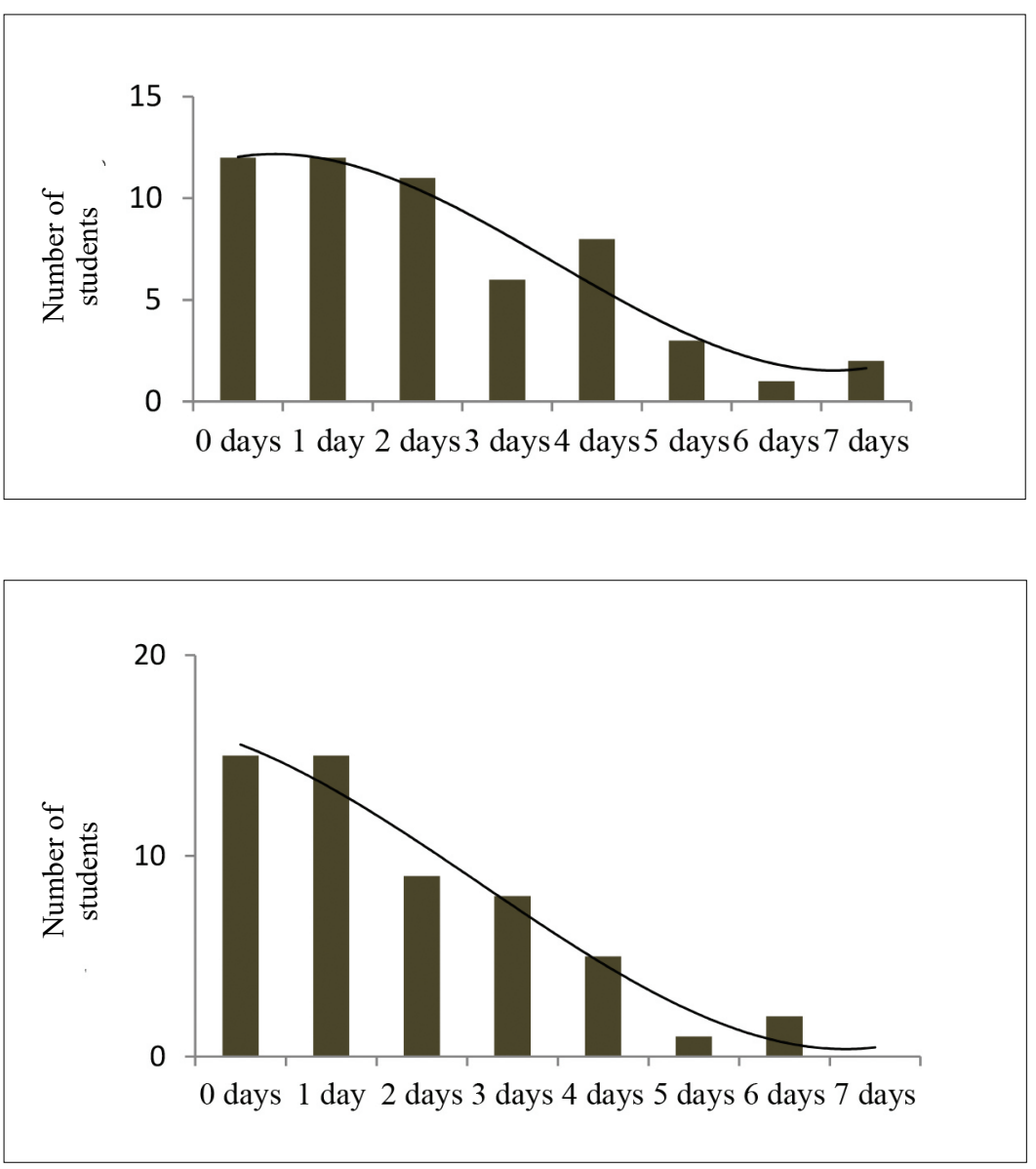

Figure 2. Frequency of doing the second mentioned sport on a weekly basis

Figure 3. Frequency of doing the third mentioned sport on a weekly basis 
Ways of doing sports. Figure 4 shows that students prefer doing sport with friends $(n=30$, $54.55 \%)$ and alone $(n=17,30.91 \%)$ to doing it with a friend $(n=8,14.55 \%)$. Test statistics showed that Chi-Square is $13.35(p<.05)$, therefore the differences are statistically significant.

Student neighbourhood analysis. Student neighbourhood was tapped with the help of several statements. Response to the Statement 1 "In my neighbourhood everyone can do sport he/she likes" is positive, students tend to agree with it (Figure 5).

Responses to Statements 2 "In my neighbourhood people's relations are good" and 3 "In my neighbourhood people help each other and support each other" are slightly less positive (for illustration See Figure 6); still the majority of youngsters tend to agree with it.

Responses to Statement 4 "In my neighbourhood the household level of well-being is high"; 5 "In my neighbourhood there is low criminality level" and 6 "In my neighbourhood the traffic is safe" follow a similar pattern: the maximum of the tendency curve is on the positive side: more students tend to agree with the statements than disagree with them, an example of the curves is shown in Figure 7.

Student neighbourhood indicator Pearson's correlation. The obtained Pearson's correlation matrix is shown in Table.

Figure 4. Ways of doing sport

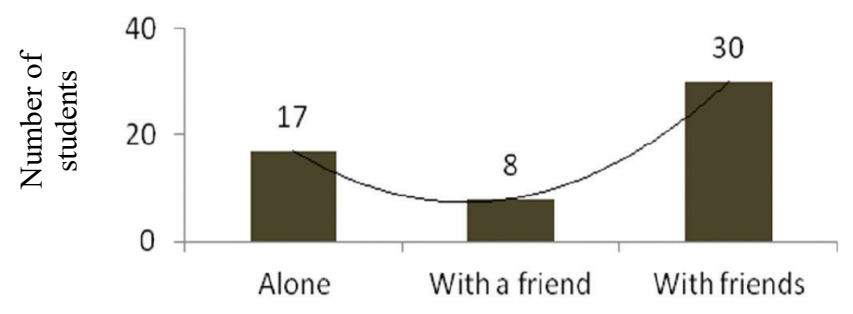

Figure 5. Response to Statement 1 "In my neighbourhood everyone can do sport he/she likes"

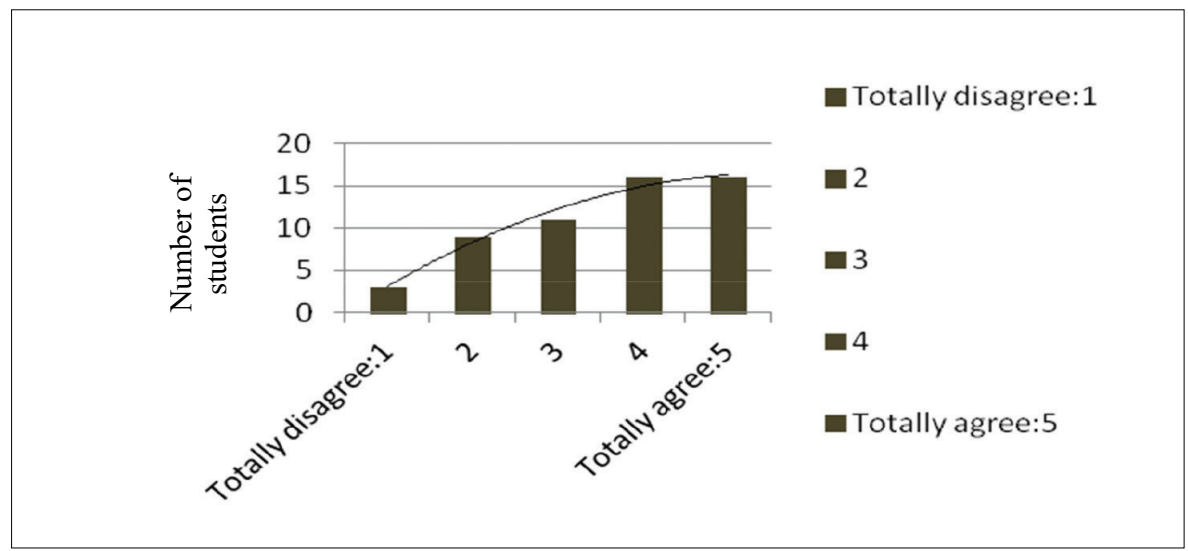

Figure 6. Response to Statement 2 "In my neighbourhood people relations are good"

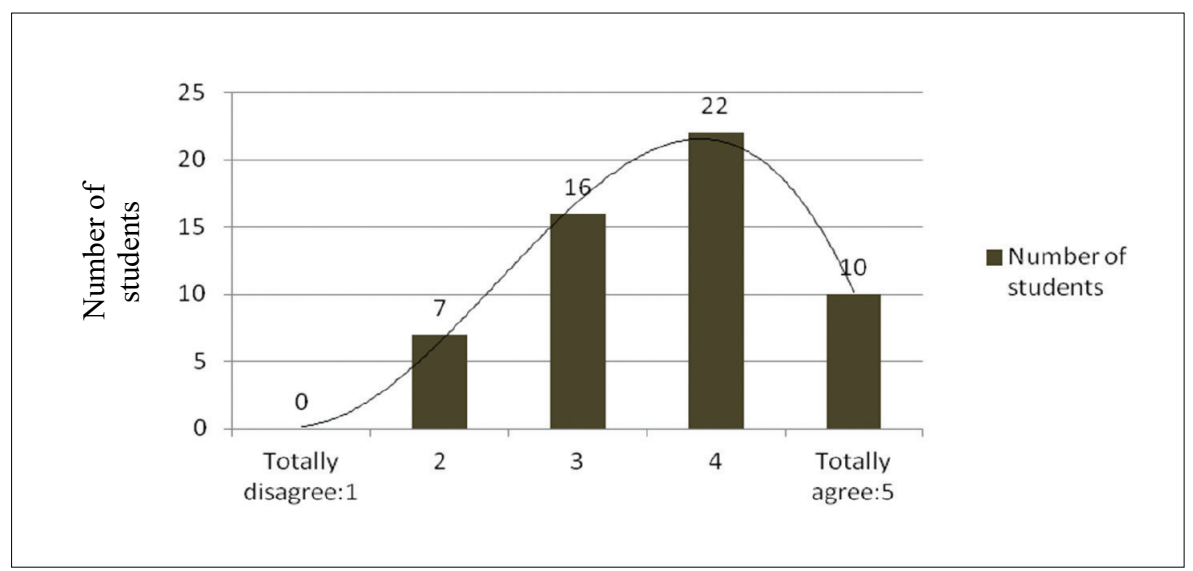




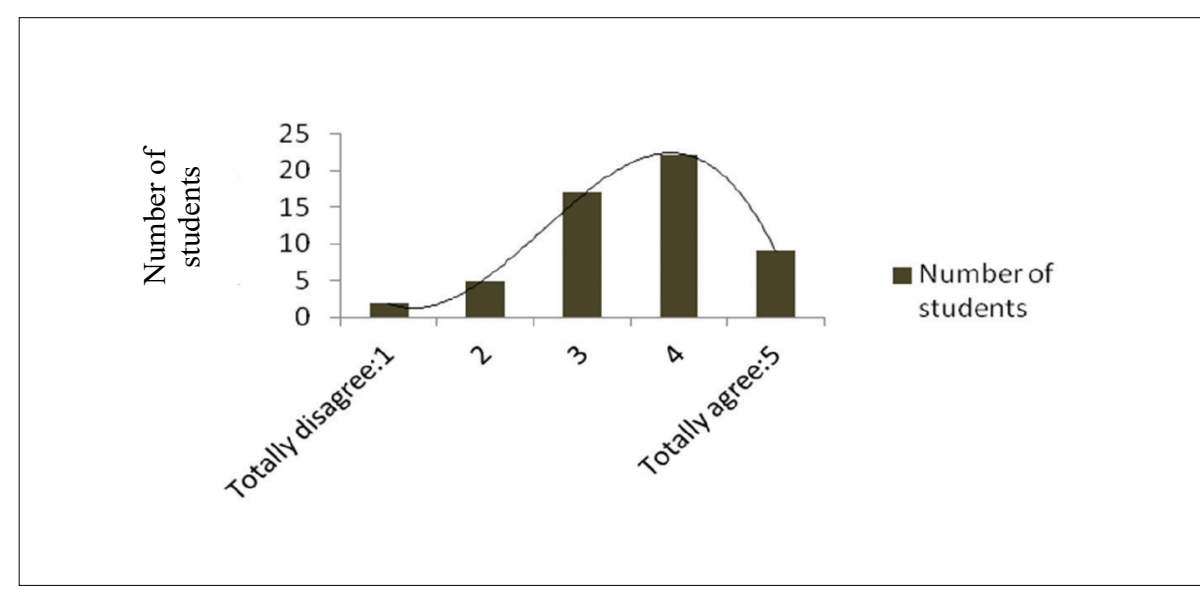

Figure 7. Response to Statement "In my neighbourhood the household level of well-being is high"

\begin{tabular}{|c|c|c|c|c|c|}
\hline \multirow[b]{2}{*}{ Indicators } & \multirow[b]{2}{*}{$\begin{array}{l}\text { Pearson's } \\
\text { Correlation }\end{array}$} & \multicolumn{4}{|c|}{ Indicators } \\
\hline & & $\begin{array}{c}\text { Good } \\
\text { relations }\end{array}$ & $\begin{array}{c}\text { Help and } \\
\text { support }\end{array}$ & $\begin{array}{c}\text { Low } \\
\text { criminality }\end{array}$ & $\begin{array}{l}\text { High well- } \\
\text { being }\end{array}$ \\
\hline \multirow[t]{2}{*}{ Good relations } & Pearson's Correlation & 1 & $.682 * *$ & $.396 * *$ & $.377 * *$ \\
\hline & Sig. (2-tailed) & & .000 & .003 & .005 \\
\hline \multirow[t]{2}{*}{ Help and support } & Pearson's Correlation & $.682 * *$ & 1 & .404 & $.480 * *$ \\
\hline & Sig. (2-tailed) & .000 & & .002 & .000 \\
\hline \multirow[t]{2}{*}{ Low criminality } & Pearson's Correlation & $.396 * *$ & .404 & 1 & .244 \\
\hline & Sig. (2-tailed) & .003 & .002 & & .072 \\
\hline \multirow[t]{2}{*}{ High well-being } & Pearson's Correlation & $.377 * *$ & $.480 * *$ & .244 & 1 \\
\hline & Sig. (2-tailed) & .005 & .000 & .072 & \\
\hline
\end{tabular}

Table. Student neighbourhood parameter correlation matrix

The results show that those who consider that their relations with neighbours are good also think that people support each other, the level of wellbeing is high and the level of criminality is low.

However, safe and friendly neighbourhood indicators do not correlate with the statement that in the neighbourhood everyone can do sport he/ she likes because students are more positive about these opportunities, but people's relations in their neighbourhood are evaluated slightly lower. The improvement of these aspects in the community might help youngsters to be more physically active.

\section{DISCUSSION}

The obtained results show that the researched youngsters of the Grade 10 of the mainstream secondary school were more physically active than in EU and in Latvia in general. In EU Special Eurobarometer 412 "Sport and Physical Activity" it was found that a majority of 15-24-year-olds exercise or play sport at least once a week, but in the present investigation it was found that on the weekly basis most of students did three sports. We consider that this result is due to the fact that the questionnaire was filled in by those students who were actively engaged in sports, but the overall engagement in sport and physical activity among the students might be lower.

In EU young people are more likely to do sports in formal settings, less common is doing sports in a park or outdoors. Although most of Latvian youngsters in a mainstream secondary school also chose to practice at sport schools, they also practiced in the parks, woods, at the seaside and at home. Youngsters preferred to practice with friends or alone to practicing with just a friend.

Most popular sports among youngsters were team games - basketball, volleyball, winter sports skiing and snowboarding, fitness sports - running, strength sports - working out in the gym, and gymnastics. The choice of the last sport might be influenced by the fact that gymnastics is now a trendy sport for young people. Moreover, it is not expensive because gymnasts mainly use only their body weight to perform stunts. A note should be made that the 1st Olympic gold medal after the renewal of independence was won by the Latvian gymnast Igors Vihrovs. Latvians are traditionally strong at winter sports, but the choice of strength 
and fitness sports might be influenced by traditional adolescent values.

Frequency analysis of the engagement in sport showed that the first sport most students did was from 2 to 6 times a week, but the second and third sport - just a few times a week.

Youngster PA habits could be influenced by the fact that they all were born in Latvia, and only three of their parents were not born in Latvia. Living conditions - a house or a flat - showed no impact on PA habits. Statistically significant, medium strong correlations were found between good relations with neighbours and high levels of well-being $(r=.38, p=.05)$.

\section{CONCLUSIONS}

The present research is among a few ones investigating relationship between physical activity regularities and neighbourhood. Physical activity regularities proved to be similar with the ones found at EU level and in separate Northern and Eastern countries. Most popular sports were found to be team sports, winter sports and running.

Youngsters chose to practice with friends or alone, rather than to practice in pairs. However, in the questionnaire family members and other relatives were not included as important others. Further surveys could benefit from such inclusion.

Youngster PA habits might be influenced the fact that they all live in their homeland, only three of the parents were from born in other countries, they tend to agree that their relations with neighbors are good and level of well-being is high.

The research was conducted in compliance with The Latvian Academy of Sport Education Ethics Commission Decision No. 2016-1.

\section{REFERENCES}

Bosdriesz, J. R., Witvliet, M. I., \& Visscher, T. L. (2012). The influence of the macro-environment on physical activity: A multilevel analysis of 38 countries worldwide. International Journal of Behavioral Nutrition and Physical Activity, 9, 110. doi: 10.1186/1479-5868-9-110

European Commission, Public Opinion, Surveys, Archives. (2014). Special Eurobarometer 412 "Sport and physical activity”. Retrieved from http://ec.europa. eu/public_opinion/archives/eb_special_419_400_ en.htm, July 19, 2016.

European Sports Charter. (1992). Retrieved from www. portal.unesco.org.

Geske, A., \& Grīnfelds, A. (2006). Izglītības pētniecība (Education research). LU Akadēmiskais apgāds.

Pinto Pereira, S. M., Li, L. \& Power, C. (2014). Earlylife predictors of leisure-time physical inactivity in mid-adulthood: Findings from a prospective British birth cohort. Medicine \& Health, American Journal of Epidemiology, 180 (11), 1098-1108. doi: 10.1093/aje/ kwu254

Prins, R. G., Mohnen, S. M., van Lenthe, F. J., Brug, J., \& Oenema, A. (2012). Are neighbourhood social capital and availability of sports facilities related to sports participation among Dutch adolescents? International Journal of Behavioral Nutrition and Physical Activity,
9, 90. Retrieved from https://ijbnpa.biomedcentral.com/ articles/10.1186/1479-5868-9-90

Sheehan, K. (2001). E-mail survey response rates: A review. Journal of Computer Mediated Communication, 6(2). doi: 10.1111/j.1083-6101.2001.tb00117.x

Tammelin, T., Näyhä, S., Hills, A. P., \& Järvelin, M. R. (2003). Adolescent participation in sports and adult physical activity. American Journal of Preventive Medicine, 24(1), 22-28. doi: 10.1016/S07493797(02)00575-5

Telama, R., Yang, X., Viikar, J., Välimäki, I., Wann, O., \& Raitakari, O. (2005). Physical activity from childhood to adulthood: A 21-year tracking study. American Journal of Preventive Medicine, 28(3), 267-273. doi: 10.1016/j.amepre.2004.12.003

Vilhjalmsson, R., \& Thorlindsson, T. (1998). Factors related to physical activity: A study of adolescents. Social Science \& Medicine, 47(5), 665-675.

World Health Organization. (2013). Physical Activity Promotion in Socially Disadvantaged Groups: Principles for Action. Copenhagen, Denmark: World Health Organization Regional Office for Europe.

Yang, X., Telama, R., Leino, M., \& Viikari, J. (1999). Factors explaining the physical activity of young adults: The importance of early socialization. Scandinavian Journal of Medicine \& Science in Sports, 9(2), 120-127.

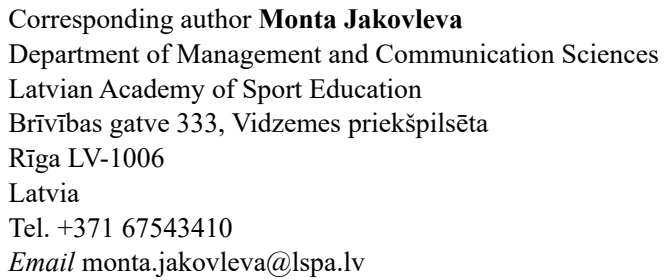

